\title{
Maternal effects on development
}

\author{
from Michael H. C. Snow
}

DURING the past 50 years the attention of embryologists has been much taken up with induction and activation. For them these terms are descriptive of the intercellular and intracellular processes whereby, presumably as the result of information received (or lost), a tissue or cell is made to modify its course of development. To the bacterial geneticist, however, induction and activation imply the mechanisms involved in the control of gene expression. Because cell differentiation depends on qualitative changes in gene activity, the terms should eventually come to mean the same to both groups. But at present the bacterial geneticist can refer to precise interactions between inducing or activating molecules and the genes themselves, while this is not possible for the embryologist dealing with higher organisms.

The current state of knowledge of these processes in embryonic development is brought into sharp focus by two recent papers. Toivonen et al. (Differentiation, 5, 49; 1976) consider inductive interactions between tissues. Primary induction whereby neural tube formation by the ectoderm is triggered by the underlying mesoderm was discovered, in Amphibia, by Spemann and his colleagues in the 1920s. They later presented evidence that an unidentified chemical substance(s) produced by the mesoderm was the effective agent (Bautzmann et al., Naturwissenschaften, 20, 971; 1932). Since then however, the existence of diffusible inductive agents has been the subject of much controversy, partly because of the difficulty experienced in repeating some of the original experiments, and more recently because Saxén and coworkers demonstrated the necessity for cell contact between tissues in the induction of kidney tubule formation (Lehtonen et al., J. Embryol. exp. Morphol., 33, 187: 1975). Nevertheless, it is now clear that cell contact is not required for the initiation of primary induction and that some diffusible macromolecular factor is involved. The exact nature of the inducer and its mode of action is still obscure.

Most if not all embryos depend for their early development on material deposited in the oocyte cytoplasm, which is subsequently used during cleavage stages. In some cases maternally derived cytoplasmic factors are required for the normal development of much later stages. Deficiences in the oocyte cytoplasm (for example, those resulting from mutation in the maternal genome) can therefore profoundly affect the development of the embryo. Several such maternal effect mutations are known in various organisms, such as the grandchildless mutant in Drosophila pseudoobscura (Spurway, $J$. Genet., 49, 126; 1948), shell coiling in the snail Limnaea (Conklin, Anat. $A n z ., 23,577 ; 1903)$ the $O$ mutant in the axolotl (Briggs and Cassens, Proc. natn. Acad. Sci. U.S.A., 55, 1103; 1966) and a recent example has been described in the DDK strain of mouse (Wakasugi, J. Reprod. Fert., 33, 283; 1973).

The interest in maternal effects stems from the observation that abnormal development occurs although the genetic constitution of the individual is normal. The error apparently results from a failure to activate certain genes during embryogenesis.

A particularly exciting example of a maternal effect gene, the $O$ gene in the axolotl is the subject of Brothers' report in this issue of Nature (page 112). The crucial observations on the $O$ gene are as follows. (1) Development is arrested in embryos derived from homozygous $\mathrm{O}$ females at the onset of gastrulation. At this time much of the embryonic genome becomes active, in particular the genes coding for ribosomal RNA. (2) The product of the normal allele $\left(\mathrm{O}^{+}\right.$factor) can be removed from the oocyte and on iniection into mutant eggs can correct the arrest at gastrulation. (3) The $\mathrm{O}^{+}$ factor is a protein and curiously is most abundant in the oocyte nucleus. What Brothers has shown, by a series of very elegant nuclear transplant experiments, is that the time of action of the $\mathrm{O}^{+}$ factor is restricted to a very short period in development of a few hours in the mid-blastula stage. If the $\mathrm{O}^{+}$ factor can be isolated and purified then the way is open to analyse the manner in which at least one inductive agent operates.
In this context it is worth noting some of the other changes found in embryos at the end of cleavage. For instance, a change has been reported in the nature of histone proteins in Drosophila melanogaster (Das et al., J. Cell Biol., 23, 423; 1964), in the snail, Helix aspersa (Bloch and Hew, J. biophys. biochem. Cytol., 8, 69; 1960) and in the mouse (Alfert, Expl Cell Res., Suppl. 6, 227; 1958). Histones are known to be potent but nonspecific repressors of transcription. Non-histone proteins on the other hand, have been postulated as being involved in derepression (activation) (Wang and Kostraba in The Role of RNA in Reproduction and Development, (edit. by Niu and Segal) 324, North Holland, Amsterdam, 1973).

The onset of gastrulation is generally accompanied by a significant change in cell proliferation rate, and in the mouse this is coincidental with a change in chromosome replication behaviour (Takagi, Expl Cell Res., 86, 127; 1974, Snow, Ciba Symp., 40, in the press). Callan has shown that in Amphibia at least, large changes in the duration of the DNA synthesis phase of the cell cycle are likely to be associated with changes in replicon length rather than changes in the linear rate of DNA replication (Callan, Proc. $R$. Soc., Lond., B181, 19; 1972, and in Molecular Cytogenetics (edit. by Hamkalo Papaconstantinou, 31, Plenum, 1973). DNA involved in replication is not available for transcription and the restriction in the number of replicating forks in the DNA may be necessary to permit transcrintion of large amounts of RNA. The $\mathrm{O}^{+}$factor could operate in either of these areas, or alternatively could be very much more specific and result perhaps in the activation of a specific gene. After 50 years of probing, a breakthrough on any front would be welcome.

\section{Role of ribosomal RNA}

from Richard Brimacombe

THE flurry of interest in bacterial ribosomal proteins over the past few years has tended rather to obscure the fact that about $60 \%$ of the bacterial ribosome consists of RNA, and many workers have tried to relegate the rRNA to a mere structural component. This attitude has arisen partly as a consequence of the dogma that proteins and not nucleic acids are the active agents in biological systems, but is also a result of the fact that, in contrast to the studies which can be made with individual ribosomal proteins, it is very difficult to devise functionally oriented experiments involving the large rRNA molecules. The idea that rRNA does indeed have an important functional role is of course not new; it was suggested some years ago by Crick and 